\title{
THE INFLUENCING FACTORS OF CHINESE MYTHOLOGICAL IMAGE CONSTRUCTION AND REPRODUCTION IN THE TRANSBAIKAL REGION
}

Artem Zhukov $^{1}$

\begin{abstract}
This article presents an investigation of the mass mentality, which exists under the influence of the Russian-Chinese transboundary relation within the territory of Transbaikalia. We have also investigated the peculiarities in the perception, of the Transbaikal population within this region, regarding the image of China and its culture. This research defines the essence of such notions as, "mentality of Transbaikal citizens" and “mythological image."

The objective of this research is to conduct a complex study of the phenomenal mythology, with respect to China, in the territory of Transbaikalia. We have identified five major factors influencing the construction and reproduction of the Chinese mythological images. As a result of this work, we have come to a conclusion that the phenomenon known as "cultural boundaries of China," which acted as a barrier, also served as a melting pot for different cultures and languages, thereby forming the most active zone for Chinese myth creation.
\end{abstract}

UDC Classification: 39 (571.54/55) (075.3), DOI: http://dx.doi.org/10.12955/cbup.v2.465

Keywords: mentality, perception, mythological image, cultural boundaries, Russian, Chinese, transboundary relation, Transbaikal region

\section{Introduction}

An interest in the Chinese culture has become increasingly prevalent today as traces of its culture have been uncovered throughout its peripheral territories, mirroring an image of a powerful civilization with a 5,000-year-long history and one of the richest cultural traditions in the East. According to Confucianism in China (1982), enormous attention to the current affairs taking place in China's bordering states is accompanied by a strong interest in the ideological and cultural influence of ancient and middle-aged China - the former state of the great Chinese nation. Contemporary Russians, residing within the territory of Transbaikalia, are also the successors of the Russian as well as the Eastern culture. Therefore, an influence by Chinese images on the Russians is deeply rooted and interconnected with the regional archetypes and traditions-long embedded into their mental perception. The subject of this investigation focuses on the mental constructions of Russian population in Transbaikalia, which have reflected their perception of China itself and Chinese people. In the section describing the mythological aspects of the research, we have made an attempt to answer the following questions: "Under which circumstances do the Russians perceive China as one image and the Chinese as another?" and "Why does the population of Transbaikalia have a peculiar tradition based on the public mentality as a nation?”

\section{Mythological images as an element of the public consciousness}

When referring to the study of "mentality," it is defined as an existing social psychology and the individual's values system (Golovanivskaya, 2009), which varies not only with individuals, but also with social and demographic diversity of the population (Bodriyar, 2006). The portrait of national and public mentality is created by social beliefs influenced by both rational and irrational factors. Vasileva (2002) pointed out that there is an impeccable correlation between mentality and language system used by the population as language is a mean of expressing one's mental development through memory.

The influential factors of life are the circumstances, which could transform views and beliefs of the entire population, such as geopolitical conditions of urbanism, cultural contacts, and social experiences. They also account for different outcomes in interpreting social affairs, making forecasts, planning, and motivating individuals to take further actions. The most evident answer to the question why the means of mental perception of various nations differed from each other is that these paradigms do not coincide in the sphere of

\footnotetext{
${ }^{1}$ Artem Zhukov, Zabaikalsky State University, Russian Federation, artyomZh@yandex.ru
} 
a symbolic system, e.g. the language system (Luriya, 1979). From a linguistics perspective, phenomena such as animation of ideas, personification of fates, materialization of grief, as well as turning an argument into a verbal weapon, are related to how people display their mythological consciousness.

One of the main functions of mentality is the perception of oneself and its surroundings. If a properly accepted image is created inside the mentality of an entire nation, which represents a legend in an undisputed picture, then any other legend would certainly be considered a myth. Thus, through these myths people more often identify themselves with self-presentation-highly organized community, with distinctive characteristics of its "own" people. During ancient times, these communities were surrounded by other people who were referred to as "alien" and even "not being people.” The perceived image of the "alien” was traditionally connected with functioning of mythological consciousness in science, the main function of which was transient-subjective to contents and images.

\section{Mythological images of China as an element of the public consciousness of the population in Transbaikalia}

Most of the citizens of the Transbaikal region know that Russian and Chinese people have different mentality based on their cultural experience. Touristic and business visits to China allow non-Chinese to experience the more exotic Chinese culture, better than through news in mass media, documentary or featured films. The specifics of the Chinese mentality are observed through a comparative study on the basic level of symbolic systems of the Russian and Chinese cultures - rituals, architecture, cuisine, and language. Even domestic studies prove that Russian and Chinese people have different perceptions over identical entities. For example, for the Russians, the government embodies an image of an awkward and ferocious bear; though moving cumbersomely, it is still dangerous to its people (Tarasova, 2012). On the contrary, for the Chinese, the personification of the state embodies a sense of care for the people by the gods.

Thus, we have noted that there is a significant difference between their philosophical systems. As a result, there exist embodied images with clear associations; the identification of which is reflected by the way people perceive and comprehend the phenomena and reality of everyday life. To the Russians, China is considered a foreign land, which exists beyond the other side of the border; life of its inhabitants is perceived as of those from out of this world. China is reflected in the minds of the Russians, firstly, as an image of the real world surrounding Russia, secondly, as a peculiar myth, based on an observation of the Chinese through their basis of interactions (Verner, 2007). Accordingly, the formation of abstract symbols, expressed as narratives and concretized in the speculation of China, occurs much later and the determination of their value depends on personal beliefs.

\section{The factors influencing the construction of the image of China in Transbaikalia}

The propagation of Chinese mythological images into the minds of the population of Transbaikalia is historically influenced by five major factors - the most significant of which is the geopolitical situation in the region. Transbaikalia occupies one of the most strategic areas of Eurasia, formed at the boundary of the largest natural geographical areas and sub-continental extra-tropical North Central Asia interaction (Natural Environmental and Man in Pleistocene, 2003). China represents the largest of the bordering oriental civilizations to Transbaikalia. Its northern borders are the interactive areas of religious, inter-civilized dialogue and cultures of the peoples in the region (Eremkina, 2010). Despite the specificity of the Chinese civilization since ancient times, it is clearly distinguishable from its mentality, religion, life's ideals, cultural values, traditions, language, and etc. Historically, there is a sphere of ethnic and cultural interaction that has invariably arisen between China and its surrounding nations.

This sphere is associated with the concept of cultural transboundary. In the analysis of the people's consciousness of Transbaikalia and Chinese cultural interaction, we have highlighted this aspect as "visible" 
and "promising,” but “foreign.” According to Bulgakov (1994), mythmaking products constitute a meeting point and borderline between the worlds - by the immanence of everyday consciousness and unattainability. They play a significant role in determining the parameters of synchronous interaction. Furthermore, they are markers that divide this space into two poles. In this study, one pole corresponds to an everyday reality, in which people in Transbaikalia live, while the other pole refers to China — possessing the main attributes of an image with unfathomably mysterious culture. "Border" is the most essential element of this space description. At the same time the notion of border with "unattainable" is ambiguous because only one side is the delimiter, but the other is linked with the unknown. Lotman (2001) noted that although the border that divides the inner world of the individual or "my" and the outer world or "foreign" should have given rise to religion and culture, in fact, it forms a myth instead. At the border of China, it is the most appropriate place to synthesize myths about China.

In this context, borderland becomes a space of various mythological existence associated with the sphere, which is situated abroad. This fact connects concepts such as "myth" and "mystery" as disclosed in the monograph by Naydysha (2002). In relation to the borderland reality of China, theoretical propositions allow us to regard "Myth of China" as a mystery, which lies beyond the borders of China with substantial evidence of human existence on this side of the border. Mysterious events occurring abroad, accompanying this mystery, are essential for the initiation of myth creation. Myth creation tool is a rational solution of the conflict or "Secrets of China" and "problems presented by China" are abroad and exist on the other side of the border. We have found that the existence of secrets is created by irrational need to satiate the curiosity of the people living on the other side of the border. In other words, there is a variety of instances in life that defies rational explanation, but the reality behind the secret lies abroad and is rather obscured. Thus, myth creation is rational and comes into play, as China is "foreign" and mysterious.

The second important factor that determines the occurrence of myth creation about China in the Transbaikal region is its use of language, in which people mix facts, imagination and personal opinion together. Even during the period of anthropological knowledge foundation development, E. Taylor substantiated a position according to different locations where each ethnic group lived, obeyed the same laws, and performed the tasks of survival, safety and welfare of procreation. Maslow (1999) agreed with this statement, and he formulated a universal model of needs, which did not report to national specificity. Positive social science data suggest that in particular, rather than invented, mythologized worlds do not have much in common. Differences come from how different people use their language to describe their existence, i.e. from their images and beliefs.

In the context of intercultural issues, occurring in the Chinese borderland, we have determined that the people of Transbaikalia have a close interaction with the Chinese civilization. Despite rather close contact between these cultures, there exist only a small number of Chinese words in the languages of the ethnic groups in Transbaikalia. Especially, a few of them are in Russian language (Naydysha, 2002). This is explained by the fact that in most cases of interethnic communication, the Chinese themselves had learned the customs and languages of those with whom they had to establish contacts. In this case, the Chinese had practically left little to no essence of their civilization on their unenlightened neighbors, who were struggling to explain and think for themselves in their native language (Osokin, 1996). In particular, the Russians of Transbaikalia always tried to communicate with the Chinese in Russian, without trying to learn Chinese, which often led to problems in interpretation, i.e. translation became a prerequisite for ethnic myth creation. A prominent example was the story of Embassy Cossack, Ivan Petlin, who brought back a letter from the Chinese Emperor, Zhu Yiyun, in 1619. The emperor was allowing contacts from Russian ambassadors in order to make trades with China. Due to the Russian's ignorance in the Chinese language, the letter was left unopened, at the embassy, still containing an unresolved riddle, until it was later translated by N. Spafaryt. As a result, an expression in Russian, “Chinese letter,” was created (Pokrovsky, 1914). 
The third factor is the propagation of images of China into Transbaikalia, which began in the Bronze Age. The region was involved in the development of Central Asian civilization, which was a separate historical and cultural region (Mikhailov, 1989). From its side, the area adjacent to Lake Baikal had long possessed some of the most important and interesting attributes of China-invariably claimimg to have increasing influence in Central Asia. Since the ancient times, China has been a subject of various peculiar myth creations, thus this phenomenon is associated with a lot of stories about gods, invisible spirits and heroes, which has long held a profound effect on the mind and hearts of the people (Verner, 2007).

Despite the fact that the tribes inhabiting the region since ancient times had differing militancy and unattainability, the processes of interaction and exchange of various mythological ideas had consistently been held with China. The Chinese's interests in the Transbaikal region during this period were much concerned with tribes of mass Turko-Mongols and Tungus-speaking nomads (Buryats, 2004). Since that time, as the Central Asian countries, their cultures and religions historically were having an impact on the consciousness of Transbaikalia; imagery, springing from the origins of Chinese culture, reflected itself in the most significant ideological symbols (Vasileva, 2002). The studies showed that the imagery of Transbaikalia, as well as that of the people of Central Asia, was significantly influenced by two ideas that had originated in the Chinese culture. The most prominent place belonged with the idea of worshiping Heaven by the Emperor, who acted as the Son of Heaven. It became a cult of Eternal Blue Sky where the hero was born, from a virgin, for the people of the region. The second idea, which came from China, was associated with Lamaism whereby priests worshipped local spirits and the spirits of ancestors. This possessed a special place in the cult of Tibetan Buddhism and was supported in the territory of Transbaikalia and Mongolia by the Manchurian government (Abaev, Feldman, \& Khertek, 2002).

The fourth is an important factor determining the characteristics of the processes of integration and assimilation of Chinese images by the population of Transbaikalia, which was the accession of these territories into Russia in the 17th century, and their subsequent coexistence. Russia was one of the largest multi-national states, preserving specific characteristics of folk and religious cultures. Loginov (2001) stated that Russian people were the largest group who, for various reasons, had arrived in the territory of Transbaikalia and were faced with the prevailing ideological complex - the elements of which for a long time were the images and symbols associated with China. We have noted that the integration processes under religious conditions led to the fact that, while forming a codependent survival, the representatives of various ethnic and religious groups had formed a certain mental unity, including the likelihood of mixed coexistence of different ideological structures. Today the Russians, comprising two interethnic groups - the Russians and the Buryats, live in Transbaikalia. These two groups have long coexisted throughout history with close interdependent communication for more than 300 years. Despite the fact that there existed a presence of complex network of identities among some of them, the predominant general identification defining those and others was "Russian," to which the other ethnic groups had joined. By the present time, most of the ethnic groups that entered into active interaction processes between the $17^{\text {th }}$ and $19^{\text {th }}$ century in Transbaikalie have merged into an externally singular-territorial community, referred to as "Transbaikalians" (Vassilieva \& Melnitskaya, 2008). The term "Transbaikalians" not only means the place of the living, but also possesses its own mentality (Konstantinov, 2013). The main characteristic has developed as a result of the long interaction between the different worlds. The community of the Transbaikalians reflected a sense of unity and, at the same time, recognition of ethnic diversity of many people living in this region. In the meantime, all these groups in the region still emulated another ethnic neighbor, the Chinese, who was always regarded as an "alien." With regard to them as a "stranger," different kinds of ethnic "stereotypes" and prejudices would spread among the Transbaikalians. Therefore, we have conducted surveys in order to understand the people's perception of an "alien," which was perceived and represented through the minds of the native people as - being on their "own.” 
The fifth, and last, developing factor of the aforementioned processes of interfaith interaction in modern Transbaikalia is the processes of interaction through globalization between Russian and Chinese cultures. The trends toward globalization of socio-cultural life of many Transbaikalians have led to the abandonment of the old ideological orientation, resulting in a crisis of national and cultural identity. Due to the changing values, orientations have been deviating from the traditional values of life, in search of new and more effective ones. Among them were values proposed by China, as one of the leading civilizations in the world, as its culture and religions were not obsolete (Beaver, 1994). The beginning of the $21^{\text {st }}$ century was marked by an increasing influence of China on the Transbaikalians; economic and cultural expansion began manifesting in many spheres of the world civilization. This fact was established by a well-known sinologist, A.G. Larin (Larin, 2008), according to whom the Russians were characterized to be in the state of panic due to the Chinese activities in the territories, which was rapidly falling outside the scope of the Russian interests. This objective has led to an outburst of activities surrounding the myth creation, its culture, and ethnic representations.

\section{Conclusion}

We have established that the formation of mythological images of China in the Transbaikal region is influenced by five major factors, among which is geopolitical-indicating the position of the region bordering between Russia and China, whose influence has been dominant for a long time in Central Asia. We have also pointed out that the presence of the "border" not only creates a barrier, but also serves as a melting pot of different cultures and languages, thereby forming the most active area of myth creation regarding China.

We can conclude that the mental perception of Chinese culture within the Transbaikal region is of a mythological nature that significantly differs from that which actually exists. Images of China and the Chinese people, created by population of the Transbaikalia, are characterized by the presence of subjective influences behind the external manifestations of myths and mysteries, which inevitably have led to the formation of a multiplicity of conflicting connotations for a regional concept of China. The impact on this sphere not only creates an ambiguous perception in the image of China for the population, but Chinese mythological creation activities also penetrate into the conscientious minds of the Transbaikal people. Chinese mythological images present in most spheres of life in the Transbaikal region have reflected a diversity of Chinese cultural influences. Therefore, the presence of diverging perceptions of mythological images of China in the minds of Transbaikalians has emerged naturally and inevitably.

\section{References}

Abaev, N. V., Feldman, V. R., \& Khertek, L. K. (2002). “Tengrianstvo” and "Ak-Chayaan” as a Spiritual Andcultural Basis of the Nomadic Civilization of Turko-Mongol Peoples of the Sayan-Altai and Central Asia. Social Processes in Modern Western Siberia. Gorno-Altaisk: RIO "Univer-Print".

Abaeva, L. L., \& Zhukovskaya, N. L. (2004). Buryats (main ed.). Moscow: Science.

Bairov, A. (2006). Shamanism in the Socio-Cultural Traditions of the Buryats. Chita: Chita State University.

Beaver, R. P. (1994). Wise Men and Immortals. Religions of China. Religions of the World. Minsk: Belfaks.

Bodriyar, Zh. (2006). Consuming Society. Its Myths and Structures. Moscow: Republic, the Cultural Revolution.

Bulgakov, S. N. (1994). Unfading Light: Contemplation and Speculation. Moscow: Republic.

Confucianism in China (1982). Theory and Practice: Collected Articles. Moscow: Science.

Encyclopedia of Transbaikalie. (2013). Transbaikalians. Retrieved November 12, 2013 from http://encycl.chita.ru/encycl/concepts/ ?id=1949

Eremkina, T. A. (2010). Traditions of Interethnic Relations in the Regional Dimension on the Example of the Transbaikal Territory. Contemporary World Politics: Perspectives from Asia. Chita: Chita State University. 
Golovanivskaya, M. K. (2009). Mentality in the mirror of a language. Some basic philosophical concepts of French and Russian. Moscow: Languages of Slavic culture.

Grach, A. D. (1980). Ancient Nomads in Central Asia. Moscow: Science.

Larin, A. G. (2008). Russian-Chinese Relations and Chinese Migrants in the Evaluation of the Russians (Continued). Problems of the Far East. 6, 81-95.

Lbova, L. V. (2003). Natural environment and man in Pleistocene (Western Transbaikalie and South - Eastern Baikal area). UlanUde: Buryat Scientific Center of the Russian Academy of Sciences.

Loginov, A. V. (2001). Multifaith. Encyclopedia of Russia. Moscow: Academic Project.

Lotman, Yu. M. (2001). Semiosphere. St. Petersburg: Arts.

Luriya, A. R. (1979). Language and Consciousness. Moscow: Moscow State University.

Maslow A. H. (1999). Theory of Human Motivation. Moscow: Eurasia.

Mikhailov, T. M. (1989). Ethnocultural Processes in the Southeast Asia in the Middle Ages. Novosibirsk: Science.

Morozova, V. S. (2013). Regional Culture in Socio-Cultural Space of the Russian and Chinese Border. Chita: Chita State University.

Naydysha, V. M. (2002). Philosophy of Mythology. From Antiquity till the Romantic Era. Moscow: Gradariki.

Osokin, G. M. (1996). Muscoviya in the East. Moscow: DI Tanais.

Pokrovsky, F. I. (1914). Travel to Mongolia and China of Siberian Cossack Ivan Petlin in 1618. St. Petersburg: Proceedings ORYAS AN, 39-40.

Tarasova, E. A. (2012). National Features of an Image of Power in the Culture of Modern Russia and China: Comparative Analysis. Russia and China: History and Prospects of Cooperation. Blagoveshchensk: Blagoveshchensk State Pedagogical University.

Vassilieva, K. K. (2002). Mentality: Ontogeny and Ethnological Dimension (on the Example of the Buryat Ethnic Group). Moscow: Russian World.

Vassilieva, K. K., \& Melnitskaya, S. A. (2008) Socio-Cultural Mentality Societies of Transbaikal Territory. Chita: Chita State University.

Verner, E. (2007). Myths and Legends of China. Moscow: Tsentrpoligraf.

Vitkovskaya, D., \& Zayonchkovskaya, Zh. (1999). New Stolypin's Policy in the Far East of Russia: Hopes and Reality. Perspectives of the Far Eastern Region: Cross-Country Interaction. Moscow: The Carnegie Moscow Center. 